\title{
Editorial Preface to the Special Issue on "The 2nd International Conference on Alternative Fuels and Energy: Futures and Challenges (ICAFE 2017)" 23rd-25th October 2017, Daegu, Republic of Korea
}

\author{
A. E. Atabani ${ }^{1} \cdot$ A. Pugazhendhi ${ }^{2} \cdot$ Ala'a H. Al-Muhtaseb $^{3} \cdot$ Takuro Kobayashi $^{4} \cdot{\text { Changsoo } \text { Lee }^{5}}^{5}$
}

Published online: 11 February 2020

(c) Springer Nature B.V. 2020

With the global population swelling and industrialization on the rise, humanity's hunger for energy has reached unprecedented levels. The world is exploring renewable energy resources such as utilization of biomass and valorisation of waste to produce both energy and products of added value. Biomass utilization systems are gaining worldwide attentions. However, in conventional researches, impacts of introducing biomass on the existing systems are not considered.

This Special Issue (SI) contains selected papers presented at The 2nd International Conference on Alternative Fuels and Energy: Future and Challenges (ICAFE 2017). The main theme of the conference was "Fuel, Energy, Sustainability-nexus". In this SI, different peer-reviewed papers covering various topics such as; Production of Biodiesel, Biogas, Biohydrogen and Bio alcohols, Characterizations of Biofuels, Production of Biofuels from Organic Waste, High Performance Electrochemical Biosensor and Simulation and Analyses of Biomass Combustion were published. A total of nine high quality papers were published in this SI.

\section{A. E. Atabani}

aeatabani@gmail.com; a.atabani@erciyes.edu.tr

1 Head of Alternative Fuels Research Laboratory (AFRL), Energy Division, Department of Mechanical Engineering, Faculty of Engineering, Erciyes University, Kayseri, Turkey

2 Head of Innovative Green Product Synthesis and Renewable Environment Development Research Group, Faculty of Environment and Labour Safety, Ton Duc Thang University, Ho Chi Minh City, Vietnam

3 Department of Petroleum and Chemical Engineering, College of Engineering, Sultan Qaboos University, Muscat, Oman

4 Center for Material Cycles and Waste Management Research, National Institute for Environmental Studies, Tsukuba, Japan

5 School of Urban and Environmental Engineering, Ulsan National Institute of Science and Technology (UNIST), Ulsan, Korea
ICAFEE series chairs are thankful to our Honorary Chair; Prof. Dr. Ashok PANDEY Editor-in-Chief of Bioresource Technology (Elsevier) for his support to ICAFEE series. We would like to deeply thank Associate Professor. Dr. SangHyoun KIM (Daegu University, Republic of Korea) and Professor. Dr. Young-Chae SONG (Korea Maritime University, Republic of Korea) for chairing ICAFE 2017 and MS/PhD students and staffs of Daegu University for their assistance in organizing ICAFE 2017. Special thanks to Prof. Dr. Ange NZIHOU (Editor-in-chief of Waste and Biomass Valorisation journal/Springer) for providing this opportunity. Thanks is also due to Ms. Ayshwarya GANESAN and Ms. Chitra VIJAYARAGHAVAN (Journal Editorial Office Assistant of Springer Nature) for their unlimited efforts during the stages of this special issue.

The Guest Editors firmly believe that this SI will be useful for researchers working on all aspects related to waste and biomass valorisation research area.

Publisher's Note Springer Nature remains neutral with regard to jurisdictional claims in published maps and institutional affiliations. 